for example, hexagonal and polar, but the two described are the simplest in use.

$$
\text { Max HAMILTON }
$$

Department of Psychological Medicine, University College Hospital, London, W.C.1. July 29.

1 Burt, Sir Cyril, "Mental and Scholastic Tests" (1921). "Vernon, P. E.. "Admiralty Notes" (1944)

Thurstone, L. L., Chesire, L., and Saflir, M., "Computing Diagrams for the Tetrachoric Correlation Coefficient" (1933).

- Pearson. K. "On the Corrclation of Characters not Quantitatively Measurable", Pror. Roy. Sor., A., 195.

\section{Feeding Mechanisms of Chironomus Larvæ}

TнE large, hæmoglobin-bearing larvæ of the genus Chironomus, commonly known as bloodworms, are the most abundant and widespread members of the bottom mud communities in ponds and lakes, but owing to the obscurity of the medium in which they live little is known about their behaviour. The larvæ live in U-shaped tubes through which an intermittent irrigation current is maintained ${ }^{1}$, and are stated to feed on the organic mud around them, eating part of the walls of their burrows or feeding off the surface of the mud ${ }^{2}$. Alsterberg ${ }^{3}$, however, considered them to be largely plankton feeders, eating algæ brought in by the irrigation current and trapped by the tube walls or the spines of the anterior proleg. But details of their feeding mechanism or respiratory behaviour are unknown. Accordingly, I have watched the behaviour of larvæ of Chironomus plumosus L. under various conditions.

Glass U-tubes, resembling in proportions those which the larvæ construct in Nature, and perforating a small celluloid platform holding a thin layer of mud (Fig. 1), housed the larvæ. Platform and tubes were placed in water in small glass aquaria. In the course of the observations a feeding method was discovered which has not previously been described. The larvæ were seen to feed largely on suspended matter filtered out of a stream of water set up through the tube by their own activity. This feeding is carried out as follows. Maintaining its position in the tube by means of firmly anchored posterior prolegs, the larva performs a number of rotatory movements of the anterior region of the body, the head describing complete circles of alternating direction round the wall of the tube. While these movements are being made the anterior proleg draws out strands of salivary secretion by rapid approach to, and withdrawal from, the mouthparts, the strands being attached to the walls of the tube and stretched across its lumen to form a loose, saucer-shaped sheet. The larva then withdraws a few millimetres down the tube, dragging with it a salivary thread from the middle of the sheet, which is thus pulled out to form a shallow conical net (Fig. 2). Attached to the thread with its mouthparts, it begins violent antero-posterior

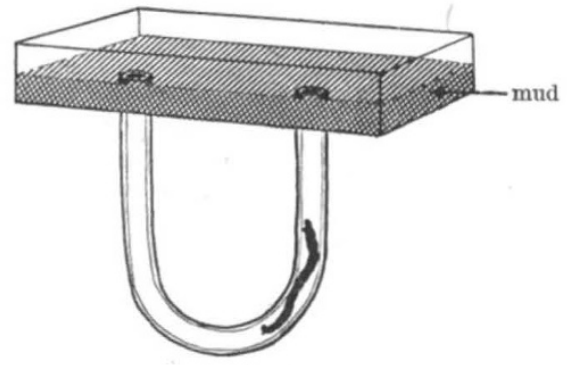

Fig. 1

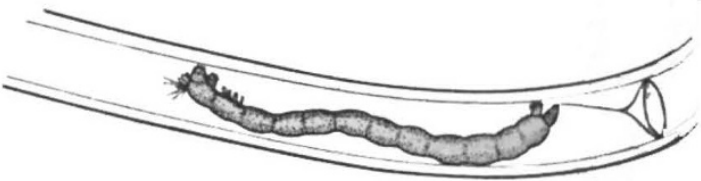

Fig. 2

undulations of the body with a frequency of about two per second. These have the effect of producing a current of water through the tube, and particles suspended in the water are caught by the conical net. The larva next straightens its body and rapidly eats the cone with the suspended matter on it; it then at once spins another web. The whole process is remarkably rapid, successive cones being formed and eaten at the rate of one every $1 \frac{1}{2} 2 \mathrm{~min}$. Approximately half the time is spent in undulating and the other half in eating and making the net. Although these time intervals vary for individual larvæ their repetition is very regular, and the whole performance forms a very stereotyped behaviour pattern which may persist for an hour or more with a regularity uninfluenced by the degree of loading of the net. More rarely, larvæ omit the net-spinning process and, instead, between the periods of irrigation, scrape the walls of their tubes which, being lined with salivary secretion, also trap particles. Very occasionally they feed from the mud surface; in doing this, they extend the body out of the tube entrance, retain. ing contact with it by means of the posterior prolegs, and spread a net of salivary secretion over the mud, which is then dragged down with its attached particles for consumption in the seclusion of the tube.

The filtering method is, however, the commonest feeding mechanism in $C$. plumosus and resembles that of leaf-mining chironomids ${ }^{2,4}$, except that in the latter the larva turns round after spinning the salivary cone, which is therefore posterior to the larva with the apex pointing away from the body. It also recalls the feeding mechanism of Urechis caupo, in which a long cone is secreted by the echiuroid worm and remains attached to the head during the irrigation of the U-shaped burrow ${ }^{5}$. In this case the cone is of mucus with pores of ultramicroscopic diameter and consequently high filtering efficiency ${ }^{6}$.

I estimated the filtering powers of the nets of Chironomus by introducing into the inhalant current a suspension of carmine, and measuring the diameter of the particles before and after passing through the tube. The nets retain all particles bigger than $17 \mu$ in diameter and most of those bigger than $12 \mu$ in diameter, and would thus trap many planktonic organisms in addition to any particles of detritus, etc., temporarily suspended in the water as a result of agitation of the mud surface. The larvæ are unselective feeders in that they eat indiscriminately all particles attached to the net.

The observations have so far been confined to the larvæ of Chironomus plumosus, but it is likely that the other closely related species have the same habits. These larvæ provide one more example of a semi sodentary animal solving the feeding problem by means of a filter mechanism.

Barbara M. WALShE

Bedford College,

University of London. Aug. 1.

${ }^{1}$ Lindroth, A., Zool. Anz., 138, 224 (1942).

'Leathers, A.'L., Bull. U.S. Bur. Fish, 38, 1 (1922).

3 Alsterberg, G., Arch. Hydrobiol., 15, 291 (1925).

- Burtt, E. 'T. Pror. Roy. Ent. Sor. Lond., A, 15, 113 (1941)

Fisher, W.K., ard MacGinitie, G. E., Ann. Mag. Nat. Hist., 10 (1928) 